\title{
Conceptualising Home-Based Child Care: A Study of Home-Based Settings and Practices in Japan and England
}

\author{
Lynn Ang ${ }^{1}$ - Mikiko Tabu ${ }^{2}$
}

Published online: 11 June 2018

(C) The Author(s) 2018

\begin{abstract}
Home-based child care or childminding as it is commonly known in the United Kingdom (UK) is a service often used by parents and families in many countries. However, despite its prevalence, there is a paucity of research on the subject. Addressing this gap, this study presents new empirical data to better understand this type of provision in supporting children's learning and development. The paper presents the findings of a qualitative study of home-based child care undertaken in five settings in Japan and England. The study examined caregivers' activities and their interactions with the children aged 4 months to 4 years. The methods included practitioner interviews, narrative observations, document analysis of activity records, and documentations of the structural and process features of the settings. The study is significant for advancing the international knowledge base of home-based child care in highlighting the service as a form of distinct, specialised care and pedagogy, as well as family support.
\end{abstract}

Keywords Home-based child care · Childminding · Early childhood · Family child care $\cdot$ Child care providers

Résumé La garde d'enfants à domicile, communément appelée «childminding»au Royaume-Uni (RU) est un service auquel les parents et les familles ont souvent recours dans de nombreux pays. Pourtant, malgré sa prévalence, il y a une pénurie

Lynn Ang

1.ang@ucl.ac.uk

Mikiko Tabu

tabum@seitoku.ac.jp

1 Department of Learning and Leadership, UCL Institute of Education (IOE), 20 Bedford Way, London WC1H OAL, UK

2 Department of Professional Teachers, Seitoku University Graduate School, 550 Iwase, Matsudo-City, Chiba 271-8555, Japan 
de recherches sur ce sujet. Afin de combler ce vide, cette étude présente de nouvelles données empiriques pour mieux comprendre ce type de prestation contribuant à l'apprentissage et au développement des enfants. Cet article présente les résultats d'une étude qualitative sur la garde d'enfants à domicile, menée dans cinq milieux du Japon et de l'Angleterre. L'étude a examiné les activités du personnel de garde et ses interactions avec les enfants âgés de 4 mois à 4 ans. La méthode comprenait des interviews avec les praticien(ne)s, des observations narratives, l'analyse de document de rapports d'activités et de la documentation sur les caractéristiques de la structure et du processus des milieux. Cette étude est importante pour l'avancement de la connaissance de base sur la garde à domicile à l'échelle internationale en faisant ressortir ce service comme forme distincte de pédagogie et de garde spécialisée, ainsi que de soutien aux familles.

Resumen Padres y familias en muchos países utilizan con frecuencia el servicio de guardería o cuidado de niños en casa como se le conoce comúnmente en el Reino Unido. Sin embargo, a pesar de su prevalencia, no existe suficiente investigación sobre el tema. Con el fin de cerrar esta brecha, el presente estudio presenta nuevos datos empíricos con el objetivo de comprender mejor este tipo de servicio y su contribución al desarrollo y aprendizaje de los niños. Este documento presenta resultados de un estudio cualitativo de cuidado de niños en casa en cinco sitios de Japón e Inglaterra. El estudio examina las actividades de los cuidadores de niños y su interacción con niños entre cuatro meses y cuatro años de edad. Los métodos incluyeron entrevistas, observaciones narrativas, análisis de documentos de registro de actividades y documentación de las características estructurales y procesales de los centros. El estudio contribuye a mejorar el conocimiento internacional sobre cuidado de niños en casa en cuanto a la percepción de este servicio como una forma especializada y única de cuidado y pedagogía de niños, así como también de apoyo familiar.

\section{Introduction}

The quality of care and education that children experience during early childhood defined internationally as the period from birth to 8 years (UNESCO 2017) is a welldocumented predictor of later development. There are short- and long-term gains for children who experience good quality care and education in a wide range of settings including centre-based and home-based settings (National Institute of Child Health and Human Development NICHD 2003, 2005; Sylva et al. 2004). This research extends the knowledge base on home-based child care by exploring the experiences of home-based child care providers across two national contexts through an ecological model of service delivery.

Home-based child care or childminding as it is more commonly known in the UK describes a type of provision where a caregiver provides a service of paid care for a 
child or group of children in a home setting (Bigras et al. 2010; Doherty et al. 2000). The provision is also variously known as 'family child care' or 'family daycare' in the international literature. The organisation for economic cooperation and development (OECD) defines the service as 'traditionally provided in a home setting. This can be at the childminder's home or at the child's own home where a qualified or registered childminder looks after the child. This type of care is most common for children prior to preschool, i.e., those up to three years old'. (OECD 2012 , p. 165). It is a commonly used service in the UK, Europe, and internationally. Yet despite its prevalence, there is a dearth of research in the area compared to the more established body of scholarship on centre-based provision. The OECD reports 'there is little data available on family day care' (OECD 2012, p. 46). Most observational studies of process features are limited to centre-based provision and '[f]ar less is known about predictors of quality for family child care homes than for child care centers' (Raikes et al. 2005, p. 164).

This paper makes a distinct contribution to the empirical research on home-based settings by presenting new data from a qualitative study of five caregivers in Japan and England and the children they care for aged 4 months to 4 years. The study explored children's everyday experiences and interactions with their caregivers in the five mixed-aged settings and explored the structural and process features of the provision. The ensuing discussion presents a subset of the findings based on the results of participant interviews and observational data which show the distinct role that home-based caregivers play in offering a specialised provision of care and pedagogy. The findings are encapsulated in an evidence-based ecological theoretical model, which depicts the dynamic intersections between the caregivers, children, and families in providing a holistic environment to support children's care, education, and overall development.

\section{Research on Home-Based Child Care}

There is growing evidence which shows the importance of home-based child care in supporting young children and families (Rusby et al. 2013; Bromer and Henly 2009; Fauth et al. 2012; Fuller et al. 2004). A comprehensive review of the international evidence revealed home-based caregivers offer a specialist service of care and family support, especially for vulnerable families (Ang et al. 2017). In England, research shows childminder provision offers positive impacts on children's development associated with higher cognitive development (verbal ability) and positive behavioural self-regulation (Melhuish et al. 2017). Results from earlier studies also point to home-based child care as providing a positive early learning environment, with caregivers supporting a continuity of care for young children between the home, school/nursery, and wider community that is so crucial for longer-term development (Mooney and Statham 2003). The general consensus among researchers is that home-based child care offers a potential resource for working parents while providing rich and diverse educational opportunities for young children's development.

Yet, while there is promising evidence of the important contribution that homebased child care makes to children's development, research also shows that the 
nature of provision varies considerably across settings and contexts. Observational studies show the variability of service experienced by families and children is often dependent on caregivers' professional values and perceived quality of care and education. Studies also highlight the divergent impact of home-based child care on children's early learning experience. For example, while earlier research from the UK and USA indicates poor quality and discontinuity experienced by children and families (Mayall and Petrie 1983; Petrie 1984; Kontos et al. 1994), more recent evidence reveals a more positive impact of home-based child care in supporting the care for young children particularly in the transition from preschool to schooling (Coplan et al. 2010; Melhuish et al. 2017).

The disparities of evidence are due in part to the complexities of measuring the quality of provision and long-term impact of home-based services on children's outcomes (Forry et al. 2013; Rusby et al. 2013). Limited comparable data of how home-based practices vary across countries and settings add to the variability of evidence. In Japan for instance, due to the limited use of home-based child care, only a small number of research studies are known. A literature search of the Japanese National Institute of Informatics database uncovered one hundred and seventy-three research articles published from 1982 to 2017. Most articles were published after year 2000 when the national funding for home-based provisions was introduced. Only a handful of articles (estimated less than three) contain comparable data either observational or statistical that focus on the actual experiences and outcomes of children compared to centre-based provision. As such, further comparative empirical work in the field is vital for advancing the knowledge base. Informed by the wider literature, the main rationale for the study was to therefore better understand the varied nature of home-based child care in two distinct country contexts in Japan and England.

\section{Context of Home-Based Care in England and Japan}

The two-country focus was driven in part by a collaboration between the researchers to explore a niche area of research in considering the complex and multifaceted dimensions of home-based child care practices that occur not only within but across settings, geographical locations, and cultural contexts. Early childhood systems differ greatly within and across countries due to varying sociocultural, economic, and policy contexts. The importance of the sociocultural contexts of child care and education is informed by existing research, which indicates early years settings are shaped by the beliefs, practices, and value systems of that society. Early childhood settings are important social and cultural institutions (Levine and New 2008; Tobin 2007), and young children's care and education are 'embedded in communities, nations, and cultures' (Tobin et al. 1989, p. 2).

In England, home-based or childminding arrangements would typically include preschool children from 18 months to 5 years, a group of mixed-age children, or at times older school-age children who attend as a form of after-school provision. Childminding providers may care for a maximum of six children under the age of eight at any one time and up to a maximum of three children under the age of five, and the service is regulated by the UK Office for Standards in Education, Children's 
Services and Skills (Ofsted). A 2016 UK child care survey (Rutter 2016) indicated that home-based child care remains an essential service for many families due to its provision of flexible child care for families. This is despite the downward trend in the numbers of home-based practitioners or childminders over the last decade (Rutter 2016). The survey report states that while an estimated five per cent of families in Britain used registered childminders as child care for a child under five, some families with school-age children 5-11 years also turn to childminders for after school care, as 'childminders are usually more flexible than after-school clubs and can often provide extra hours of child care' (Rutter 2016, p. 18). This wraparound care remains a distinct feature of home-based provision.

In Japan, home-based child care caters specifically for children under the age of three. Regulations allow for a ratio of one caregiver to three children or five if child care assistants are recruited to work alongside the main provider or caregiver. The country has an established history of institutionalised care and education dating back to the late nineteenth century and of state-funded child care provisions for disadvantaged families since the turn of the twentieth century. The service is delivered and funded at municipal level (equivalent to the English local authority) where municipalities have sole responsibility for maintaining the service and delivery of provisions including the quality assurance and training of providers. Home-based caregivers listed in the national registry are considered independent providers and contracted directly by the municipalities where they reside. Child care regulations which govern some of the structural and caregiver characteristics of home-based settings vary across countries. A broad overview of the key regulatory features in England and Japan is provided in 'Appendix'.

\section{Research Aims and Questions}

The overall aim of the study was to examine the quality of care and education that is associated with positive learning and early experience for children in home-based settings, as well as practitioners' perceptions of their role as caregivers. The study examined characteristics of home-based child care in terms of structural, process, and contextual dimensions (Bigras et al. 2010). Structural features typically entailed, for instance, the age group of children, child-caregiver ratios, and caregivers' qualifications and training. Process features included observable data of children's experiences and interactions with caregivers, while contextual features encompassed the sociocultural and context-specific dimensions that were perceived to be distinct to the local settings in each country. The study was framed by the following questions:

1. How do home-based practitioners in England and Japan support the care and education of children?

2. What are practitioners' perceptions of the features that constitute quality care and education and how do these shape their practices?

3. What are the experiences of young children in home-based settings? 


\section{Methodology}

\section{Sample}

A purposive sample of five settings comprising two in England and three in Japan was recruited through the targeted local authority in England or municipality in Japan. All home-based providers are experienced, established caregivers having been long-standing practitioners in the profession ranging from 5 to 22 years. Two participants are degree graduates, and three have post-compulsory further education qualifications. All participants offer full-time child care, with one of the English participants offering part-time after-school and holiday care to a few older children. The children in the settings ranged from 18 months to 5 years. While the English childminders operated as sole caregivers, the Japanese providers tended to have additional two to three assistants at any one time whom they recruited to work alongside them in the settings to provide additional help with the children. This difference in child-adult ratios accounted for some of the structural variations but was considered independently of the process measures given the main focus of the study was to understand the caregivers' everyday practices and children's experiences in the settings.

\section{Ethical Considerations}

In undertaking the study, the researchers were guided by the professional code of conduct of the British Education Research Association (BERA) and the Social Research Association (SRA) which adhere to the basic tenets of do no harm and respect for all persons involved in the research (BERA 2011). The study was formally approved by the UCL Institute of Education Research Ethics Committee. Prior to the study, informed consent was sought from all participants, including the parents of children who were included in the observations. Participants were informed of their rights to withdraw at any stage of the study, and all given names are pseudonyms in the presentation of this paper.

\section{Data Collections and Analysis}

The methodology was qualitative and exploratory, using caregiver interviews, observations, and documentary analysis of journal diaries and activity records of the children. Observations were undertaken four to six hours at a time during each setting visit. The standardised rating tool-the Family Day Care Rating Scale (FDCRS) (Harms and Clifford 1989) - a commonly used observational instrument, was adapted to examine predetermined quality indicators of structural and process features of the setting's provision. The observations focused on a range of contextual and process features found in earlier studies to be related to good quality provision such as child and caregiver interactions, caregivers' attentiveness and responsiveness, as well as learning activities. During the observations, descriptive and reflective field notes were also taken (Creswell 2005). For purposes of 
reliability, both researchers undertook the field work jointly in all settings. The observation and interview tools were piloted and then moderated to enhance their validity.

Caregiver interviews of forty minutes to an hour were collected through informal, conversational interviews (Gray 2014) during the setting visits to gather basic demographic information about some of the structural features of provision such as the number of children, qualifications and level of experience, training, professional backgrounds, and reasons for choosing the profession. Follow-up interviews after each visit were conducted with participants to gain more comprehensive data and extend any issues that arise from the observation records such as caregivers' beliefs and values of care and education, their activities and routines to gain an insight into their daily practice. In addition to the observations and interviews, documentations of practice were also collated which included daily journals, activity records, and any written and/or oral reflections that the caregivers maintained as part of their practice. The document analysis was useful for the triangulation of data and shedding new insights into the caregivers' daily practices. The composite data set was analysed with reference to codes and themes in a reiterative process with the research questions as a guide. The findings and themes were then drawn together to inform an emerging conceptual framework (see Fig. 1).

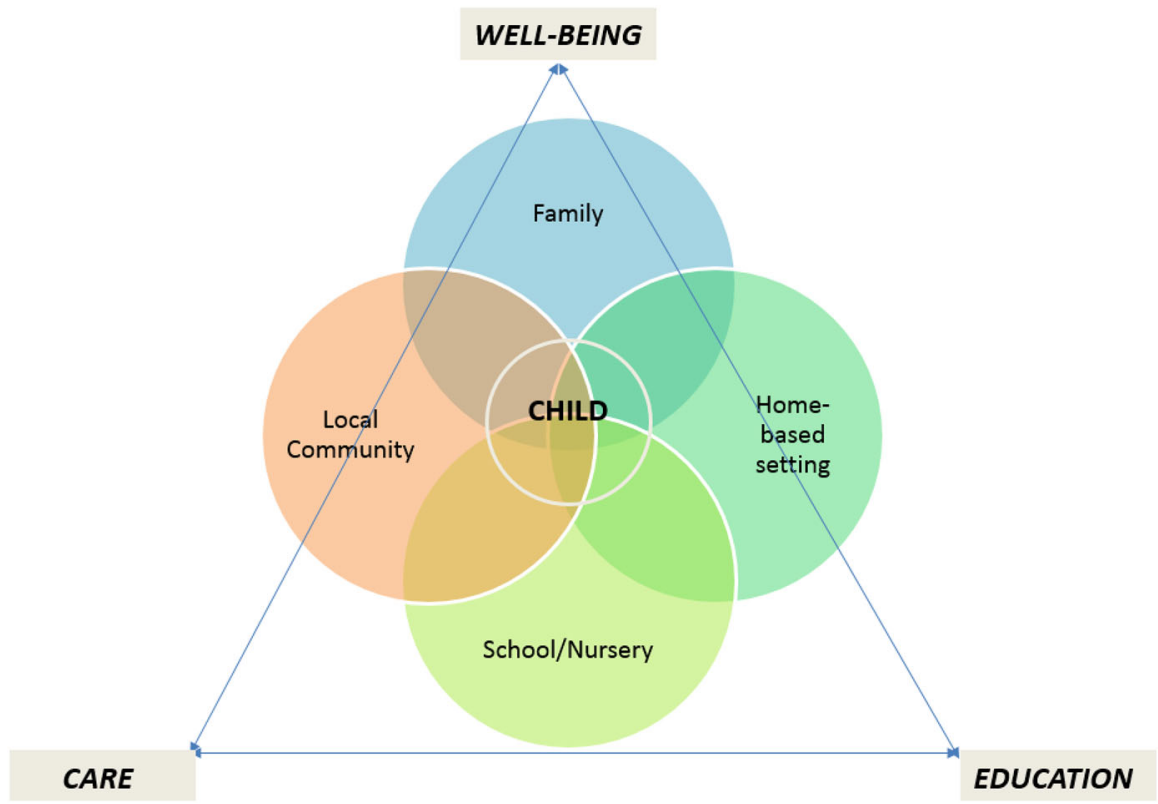

Fig. 1 Ecology of childminding 


\section{Findings}

\section{Conceptualising Home-Based Child Care}

The main aim of the study was to examine the features of home-based child care that constitute quality care and education, and to better understand the kinds of everyday experiences that children have in this type of setting. The findings add to a growing body of research that shows the role of home-based services as offering ecology of support and care for young children and their families. The conceptual model depicted below presents an analytical framework for depicting the multiple intersecting and overlapping dimensions of the family, local community, school/ nursery, and home-based setting that work together to create a holistic care and support system to enhance the care, education, and overall well-being of young children.

Based on the conceptual model, the findings identified three central themes which were identified from the analysis as particularly interesting in conceptualising home-based child care services in terms of: (1) a personalised care and education support service for children and families; (2) a distinct pedagogy in supporting young children's learning; and (3) a community of practice supported by a closeknit group of home-based caregivers.

\section{Personalised Support Service for Children and Families}

A key theme that emerged from the data is the role of home-based child care as providing a personalised care and education support service for children and families on multiple levels. When asked about how they perceived their work as home-based providers, all participants emphasised the close interpersonal and personalised relationship they have with the children and families as the core of their service. The formal yet flexible arrangements offered by caregivers in all five settings were pivotal in providing vital support for parents when managing the daily logistics of child care, work, and family life. Examples of personalised support offered by all five caregivers included flexible child care hours including extended hours, assistance with daily routines such as school runs and after-school care in the case of the English settings, supporting the children's transition to nursery, flexible fee payment schemes, and other related practical support for working parents.

The findings showed at the heart of home-based provisions are the close relationships established between caregivers with parents and families, as substantiated by existing research as a distinct and important dimension of home-based settings (Fauth et al. 2012). For instance, Katherine, an experienced English childminder with over 15 years of experience, discussed the close rapport she has with parents:

It is more important for me to have a connection with the mum or the dad, because everything else follows as well. We need to work together. ...I love my parents. Every single parent that I have I get along so well with. They are on the same wavelength as me. I am honest with them. I am open with them. 
They like that. They like the fact that they can have a conversation with me for ten minutes at the end of the day, but not just about their child but about their actual day. I think that is really important'.

Katherine was keen to emphasise her close engagement with parents and attributes the level of trust between herself and her parents as indicative of the quality of the service that she provides. Her willingness to initiate interaction and conversations to build rapport with parents was noted in the observation notes during the setting visits.

In offering a personalised support service, Haruko a Japanese home-based caregiver stressed the importance of meeting the needs of parents and supporting their child's development:

I am trying to be an auntie of the children I look after. So, I tell parents to call me by my nickname; in a nursery-centre parents normally call the staff "teacher". I would like to meet parent's requests as much as possible. ... At the moment, I have a child whose mother brings her late in the morning, or comes to pick her up early in the afternoon. It does affect the outing schedule or lunch time of other children. But I understand the mother's home situation and I accept her routine as much as possible. It is not because she is a customer of my service, but I want to be a person like her relative. Then it is a natural thing to be as supportive as possible.

Participants also talked openly about their feelings of responsibility to the families they work with, and reciprocity as an integral part of their relationship in supporting parents manages the demands of work, child care, and at times financial pressures as in the case of the English childminders Anne and Katherine. When asked specifically about their fees and child care payments, and how they interacted with families around child care costs, both Anne and Katherine emphasised their consideration of individual parents' financial circumstances and willingness to offer concession with flexible payment. As Karen explains:

I consider people's circumstances. I might charge one person one amount, another person a different amount, because I am aware of their personal situation. I do [have different set rates] When they start with me, if somebody was to call me now, I will tell them my day rate. But some of the parents that I already have, I know that things may be tight, and I am aware that things have been difficult. So I try to take into that account and I haven't increased my fees. I knew that if I approach one parent, they would find it a real struggle'.

The offer of a personalised support service alongside a close and trusting relationship between childminders, children, and parents is therefore a core feature upon which all caregivers in the study perceived good home-based provision to be. All caregivers in the study revealed the extent to which they personalise their care based on what their parents want as integral to their service. All participants unanimously cited their close engagement with children and parents as a way of making a positive impact on the lives of children and families. 


\section{A Distinct Pedagogy in Supporting Young Children's Learning and Education}

The findings also show emerging evidence of home-based child care as offering a distinct form of pedagogy in supporting young children's learning and development. The concept of 'pedagogy' is defined here as the 'act and discourse of teaching' (Alexander 2004, p. 8) and a social process that is enacted within a discursive and dialogic space of a learned community (Lave and Wenger 1991; Holland and Lave 2009). This underpinning concept of pedagogy as a social practice offers a useful theoretical framework and more nuanced understanding of the myriad ways in which learning takes place in home-based settings. The data showed that pedagogy, as a discursive act of learning and teaching being enacted by the practitioners in their everyday practice in their interactions with the children.

Participants in the study were observed to encourage social interactions and learning across the mixed age range. All caregivers were perceived to tailor their support of children's learning in a variety of ways from setting up of daily learning activities to organising days out on educational visits. Caregivers' daily activities showed evidence of a wide variety of educational activities that varied from day to day. For instance, Katherine provided a carefully planned programme of daily and monthly activities in advance that was suited to the children's interests, and which she would document in a monthly newsletter to parents. Anna, on the other hand childminder preferred a more flexible approach of a combination of spontaneous and guided free play activities to offer educational opportunities for the children in her care.

In Japan, a wide range of pedagogical activities were exemplified in the daily activities of the three family day-care settings. Natusko, for instance, emphasised the importance of planning a structured schedule of activities to engage children in

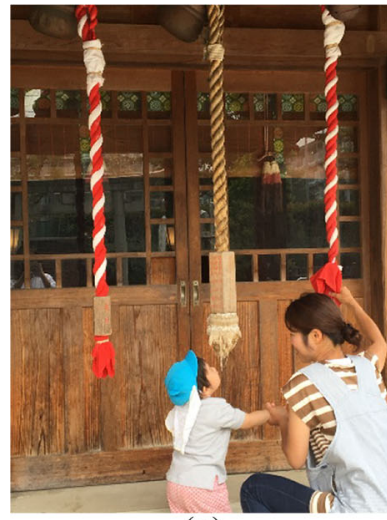

(a)

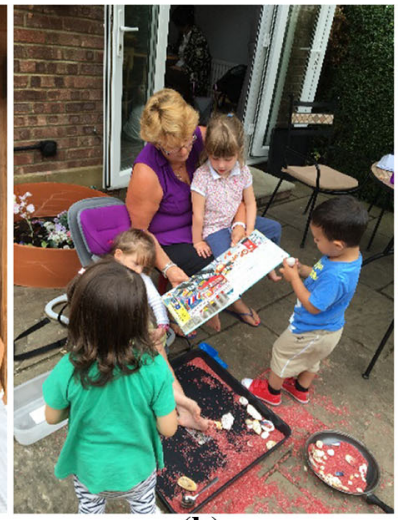

(b)

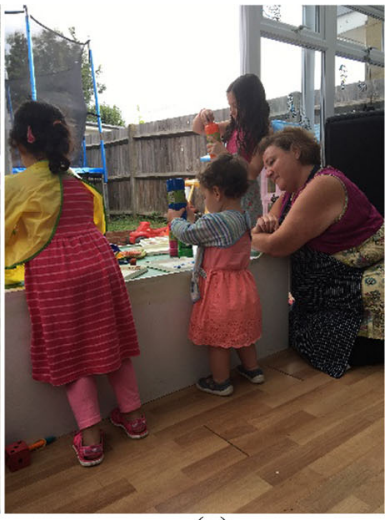

(c)

Fig. 2 a Children in Japan on a visit to a local shrine. b Children in England enjoying a book-reading activity. c Children engaged in informal learning activities. (Photographs taken with permission from child and adult participants) 
their local culture and community. For instance, outdoor play outings usually included an obligatory visit to the local shrine in the neighbourhood, as depicted in Fig. 2a. Natsuko describes her role in enhancing children's learning in terms of not just her provision of educational opportunities but exposure to cultural experiences and local practices, as well as supporting her children's transition to day nursery:

Because the children I look after are small, I consider my primary role is to ensure and enhance the child's healthy development. ... I think it quite important for me to have a plan not only for the activities for the next day or a week, but also work towards the day the child graduates here at the age of three, and move to a large nursery-centre. (Natuksko)

Figure 2a-c illustrates the myriad activities observed during the setting visits which showed the support offered by caregivers in enhancing the learning and cognitive development of the children.

The findings therefore show a mix of activities and routines offered by childminders as comprising a rich pedagogy and learning environment that is tailored to the children's interests and needs. It could be argued that the everyday routine of home-based settings that is at times unpredictable, with a less-structured curriculum, learning provision in a small group of mixed-age peers, and other features of home-based provision provides a distinct pedagogical experience for children than that of centre-based day care where children have multiple caregivers and are often grouped with same-aged peers in larger group sizes. All caregivers in the study felt strongly of their role in supporting learning and preparing children for nursery or school as an important part of their work. Crucially, the data indicated the childminders perceived an important part of their role in working with parents to support learning and allowing children to have a voice in what they learned and how they learned it, and a clear recognition of their roles as home-based care-givers as providing more than 'just care'.

\section{A Community of Practice Supported by a Close Knit Group of Home-Based Caregivers}

A third and final theme is that of home-based caregivers working within a close-knit community of practice. There was clear evidence of caregivers working together within their local authority or municipality to support each other's practice and utilising networks within the community such as play groups and children's centres to support their delivery of care and education. Katherine explains the support she gains from other childminders in her area which she finds invaluable for both herself and the children:

We get together, we see each other probably 3 times a week at a minimum where we go to the either to the children's centre, to a childminding group for the children run only by childminders for childminders. And we also go out on days out. So in the summer times when playgroups aren't on, we get together we meet up. And then we are all working together. So the children are not only 
with me, they are with their social group. It is not just the children I am caring for.

The Japanese caregiver Natsuko describes the organised activities and events that she participates in with a group of home-based providers in her local community for professional support, while Fuyuko another caregiver emphasises the importance of being part of her local community of practitioners, which comprises an association of 24 providers, all of whom work for the same Kawasaki-city municipality, south of metropolitan Tokyo, and get together every third Saturday of the month for training and professional development events such as workshops and seminars with invited speakers on new early years policies. Additionally, the camaraderie experienced by the group of caregivers goes beyond professional support but in galvanising support for each other with concerted campaigns to raise the profile of home-based child care in the municipality. Like the English childminders, Fuyuko also benefited from support from her local child care networks such as the local centre-based day nursery where she has an established relationship with the staff in sharing their activity plans and organising joint activities for the children.

I go regularly to the day nursery with my children, once a week or so, to enjoy the outdoor space and play equipment. They are invited to the activities outdoors and sometimes indoors. It is good for them because they get used to a bigger place and a larger group. All my children, by regulation, have to leave my nursery soon after they reach three. So, for bigger children who go to a centre-based place in a few months of time, it's important to meet other children of their age.

I feel great too, to see experienced teachers to talk to. Sometimes, I want advice about a child who might need extra help. For example, I have 2 yearold boy, and the others happen to be much younger. I am worried if he has enough learning/play opportunities appropriate to his age. When I tell my concern, the teachers will observe him and tell me what they find about him. It helps me to see him in a different way and have a new idea to work with him.

The mutual support and collaboration shared by caregivers in both the English and Japanese settings indicate the extent to which home-based child care takes place most effectively in a community of practice where participants are engaged in a social network of support with other caregivers in a way that not only benefits them but the children.

\section{Conclusion}

In a relatively understudied area compared to centre-based child care, this study of home-based child care is significant in advancing our knowledge about this type of provision. The targeted sample of home-based caregivers enabled the researchers to focus exclusively on the five providers but the purposive sampling meant the 
findings are non-representative and not generalizable. While the variations in early childhood systems and governance in Japan and England offered interesting insights, the comparability of the findings is restricted given the limited diversity and variable cultural and contextual influences that may mediate the quality of home-based child care across the settings. Due to the defined scope and timeline of the study, it is not feasible to delineate the impact of home-based settings on children's longer term outcomes.

The evidence presented demonstrates the potential role of home-based child care in offering vital support for young children, families, and in particular working parents in two distinct countries in Japan and England. The findings showed an ecological model of home-based child care across two distinct cultures that encapsulated the multiple dimensions that influence children's early care and educational experience. Despite the difficulties in drawing causal links between the characteristics of care and the impact on children's longer term outcomes, the findings suggest that in all likelihood, home-based caregivers who work in a community of practice and have established strong, close relationships with the children and parents have the propensity to offer a positive and enabling quality early years educational experience.

Acknowledgements This project was supported by the Daiwa Foundation [Ref 10728/11468] and Japan Society for the Promotion of Science (JSPS) Grant-in-Aid for Scientific Research [Ref 26381096]. We would also like to acknowledge the childminders, children, and parents who have so generously given their time to participate in the research and welcomed us into their worlds.

Open Access This article is distributed under the terms of the Creative Commons Attribution 4.0 International License (http://creativecommons.org/licenses/by/4.0/), which permits unrestricted use, distribution, and reproduction in any medium, provided you give appropriate credit to the original author(s) and the source, provide a link to the Creative Commons license, and indicate if changes were made. 


\section{Appendix}

\begin{tabular}{|c|c|c|}
\hline & Japan & England \\
\hline $\begin{array}{l}\text { Compulsory } \\
\text { education }\end{array}$ & $6-15$ years & $5-16$ years \\
\hline $\begin{array}{l}\text { Supervisory } \\
\text { authorities }\end{array}$ & $\begin{array}{l}\text { Ministry of Health, Labour and Welfare \& } \\
\text { Cabinet Office, Government of Japan } \\
\text { Municipality }\end{array}$ & $\begin{array}{l}\text { Department for education } \\
\text { Local authority }\end{array}$ \\
\hline $\begin{array}{l}\text { Use of home- } \\
\text { based child } \\
\text { care }\end{array}$ & $\begin{array}{l}\text { Subsidised registration: home-based child } \\
\text { care providers are self-employed, but } \\
\text { their provision is maintained by } \\
\text { municipalities under contract }\end{array}$ & $\begin{array}{l}\text { Registered childminders: 43,500 [Source: } \\
\text { Ofsted (2017), child care providers and } \\
\text { inspections, Manchester: Ofsted] }\end{array}$ \\
\hline Age of children & $0-2$ years & $0-8$ years and over \\
\hline $\begin{array}{l}\text { Child/adult } \\
\text { ratio }\end{array}$ & $\begin{array}{l}\text { Max } 3 \text { alone } \\
\text { Max } 5 \text { with an assistant } \\
\text { No provider who has children under } \\
\text { school age ( } 6 \text { years) is permitted to offer } \\
\text { home-based child care }\end{array}$ & $\begin{array}{l}\text { Max } 6 \text { under } 8 \text { years } \\
\text { Max } 3 \text { under } 5 \text { years } \\
\text { Only } 1 \text { under } 1 \text { year } \\
\text { Provider's own children may be included }\end{array}$ \\
\hline Cost & $\begin{array}{l}\text { Parents pay according to the household } \\
\text { income (eight divisions) }\end{array}$ & $\begin{array}{l}£ 104.27 \text { per week for part-time care, } \\
\text { although varies by region and provider } \\
\text { [Source: Rutter (2016). } 2016 \text { Survey of } \\
\text { child care and early years providers: } \\
\text { London: Department for Education] }\end{array}$ \\
\hline Working hours & $\begin{array}{l}\text { Average } 8 \text { h daily (additional hours } \\
\text { available) }\end{array}$ & $\begin{array}{l}8 \mathrm{~h} \text { daily (additional hours available by } \\
\text { arrangement) }\end{array}$ \\
\hline $\begin{array}{l}\text { Space for } \\
\text { children }\end{array}$ & $\begin{array}{l}\text { Indoor: one room, minimum } 9.9 \text { sqm, for } \\
\text { up to } 3 \text { children; } 3.3 \text { sqm/additional } \\
\text { child } \\
\text { Outdoor: none specified }\end{array}$ & $\begin{array}{l}\text { Under } 2 \text { years ( } 3.5 \text { sqm/child; } 2 \text { years: } \\
2.5 \text { sqm/child; } 3-5 \text { years: } 2.3 \text { sqm/ } \\
\text { child) } \\
\text { Outdoor: none specified }\end{array}$ \\
\hline $\begin{array}{l}\text { Support by } \\
\text { authority/ } \\
\text { quality } \\
\text { assurance }\end{array}$ & $\begin{array}{l}\text { Locally determined on national standards } \\
\text { and regulations: financial support for } \\
\text { setting up; fund for the cost for } \\
\text { provisions; providing pre- and in-service } \\
\text { training; providing substitute care; } \\
\text { ensure collaboration with a day nursery; } \\
\text { supervisory visits twice a year }\end{array}$ & $\begin{array}{l}\text { Locally determined by local authorities: } \\
\text { monitoring and information service; } \\
\text { free advice and supervisory visits; } \\
\text { training program; childminders' drop-in } \\
\text { centres; Ofsted registration and } \\
\text { inspection }\end{array}$ \\
\hline
\end{tabular}




\section{References}

Alexander, R. (2004). Still no pedagogy? Principle, pragmatism and compliance in primary education. Cambridge Journal of Education, 34(1), 7-33.

Ang, L., Stephen, C., \& Brooker, L. (2017). A review of the research on childminding: Understanding children's experiences in home-based child care settings. Early Childhood Education Journal, 45, 261-270. https://doi.org/10.1007/s10643-016-0773-2.

Bigras, N., Bouchard, C., Cantin, G., Brunson, L., Coutu, S., Lemay, L., et al. (2010). A comparative study of structural and process quality in center-based and family-based child care services. Child \& Youth Care Forum, 39(3), 129-150.

British Educational Research Association (BERA). (2011). Ethical guidelines for educational research. London: BERA.

Bromer, J., \& Henly, J. (2009). The work-family support roles of child care providers across settings. Early Childhood Research Quarterly, 24, 271-288.

Coplan, R., Findlay, L. C., \& Schneider, B. H. (2010). Where do anxious children " fit'” best? Child care and the emergence of anxiety in childhood. Canadian Journal of Behavioural Science, 42, 185-193. https://doi.org/10.1037/a0019280.

Creswell, J. W. (2005). Educational research: Planning, conducting, and evaluating quantitative and qualitative Research (2nd edn.). Upper Saddle River, NJ: Pearson Education.

Doherty, G., Lero, D. S., Goelman, H., Tougas, J., \& LaGrange, A. (2000). Caring and learning environments: Quality in regulated family child care across Canada. Guelph: Centre for Families, Work and Well-Being, University of Guelph.

Fauth, R., Owen, S., \& Jelicic, H. (2012). The next best thing to being at home: Parents' view of quality in home-based child care settings. Research summary. London: NCB Research Centre.

Forry, N., Iruka, I., Tout, K., Torquati, J., Susman-Stillman, A., Bryant, D., et al. (2013). Predictors of quality and child outcomes in family child care settings. Early Childhood Research Quarterly, 28, 893-904.

Fuller, B., Kagan, S. L., Loeb, S., \& Chang, Y. W. (2004). Child care quality: Centers and home settings that serve poor families. Early Childhood Research Quarterly, 19, 505-527.

Gray, D. E. (2014). Doing research in the real world. London: Sage.

Harms, T., \& Clifford, R. M. (1989). Family day care rating scale. New York, NY: Teachers College Press.

Holland, D., \& Lave, J. (2009). Social practice theory and the historical production of persons. Actio: An International Journal of Human Activity Theory, 2, 1-15.

Kontos, S., Howes, C., Shinn, M., \& Galinsky, E. (1994). Quality in family child care and relative care. New York, NY: Teachers College Press.

Lave, J., \& Wenger, E. (1991). Situated learning: Legitimate peripheral participation. Cambridge: Cambridge University Press.

Levine, R., \& New, R. (Eds.). (2008). Anthropology and child development: A cross-cultural reader. Oxford: Blackwell Publishing.

Mayall, B., \& Petrie, P. (1983). Childminding and day nurseries: What kind of care?. London: Heinemann.

Melhuish, E., Gardiner, J., \& Morris, S. (2017). Study of early education and development (SEED): Impact study on early education use and child outcomes up to age three. London: Department for Education.

Mooney, A., \& Statham, J. (Eds.). (2003). Family day care: International perspectives on policy, practice and quality. London: Jessica Kingsley Publishers.

National Institute of Child Health and Human Development (NICHD) Early Child Care Research Network. (2003). Does quality of child care affect child outcomes at age $4 \frac{1}{2}$ ?'. Developmental Psychology, 39, 451-469.

National Institute of Child Health and Human Development (NICHD) Early Child Care Research Network. (2005). Child care and child development: Results from the NICHD study of early child care and youth development. New York, NY: Guilford Press.

OECD (Organisation for Economic Co-operation and Development). (2012). Starting strong III: a quality toolbox for early childhood education and care. Paris: OECD.

Ofsted. (2017). Childcare providers and inspections. London. Retrieved from https://www.gov.uk/ government/publications/childcareproviders-and-inspections-as-at-31-december-2017. 
Petrie, P. (1984). Day care for under 2's at childminders and in day nurseries. Early Childhood Development and Care, 16, 205-216.

Raikes, H. A., Raikes, H. H., \& Wilcox, B. (2005). Regulation, subsidy receipt and provider characteristics: What predicts quality in child care homes?'. Early Childhood Research Quarterly, 20, 164-184.

Rusby, J. C., Jones, L. B., Crowley, R., \& Smolkowski, K. (2013). The child care ecology inventory: A domain-specific measure of home-based child care quality to promote social competence for school readiness. Early Childhood Research Quarterly, 28, 1-13.

Rutter, J. (2016). 2016 Child care survey. London: Family and Child Care Trust. Retrieved from https:// www.familyandchildcaretrust.org/childcare-survey-2016-0.

Sylva, K., Melhuish, E., Sammons, P., Blatchford, I.-S., \& Taggart, B. (2004). The effective provision of pre-school education [EPPE] project (Project Final Report). London: DfES/Institute of Education, University of London.

Tobin, J. (2007). An ethnographic perspective on quality in early childhood education. In J. X. Zhu (Ed.), Global perspectives on early childhood education. Shanghai: East China Normal University Press.

Tobin, J., Wu, D., \& Davidson, D. (1989). Preschool in three cultures: Japan, China, and the United States. New Haven, CT: Yale University Press.

UNESCO. (2017). Early childhood care and education. Paris: Author. Retrieved from https://en.unesco. org/themes/early-childhood-care-and-education. 